\title{
The importance of science communication in cancer research: an interview with Martin Christlieb
}

\author{
Martin Christlieb *,1 \& Roshaine Wijayatunga ${ }^{2}$ \\ ${ }^{1}$ Department of Oncology, Old Road Campus Research Bldg, Roosevelt Drive, Oxford OX3 7DQ, UK \\ ${ }^{2}$ Future Science Group, Unitec House 2 Albert Place, Albert PI, London N3 1QB, UK \\ *Author for correspondence: martin.christlieb@oncology.ox.ac.uk
}

\begin{abstract}
"Scientists need to see engagement as part of their development. This is an amazing way to develop communication skills and scientists need to take that opportunity"
\end{abstract}

\begin{abstract}
I trained as a chemist, studying for a PhD at the University of Cambridge. After I left Cambridge, I undertook postdoctoral appointments at Stanford and Oxford. These appointments led me into metal chemistry, initially using the metals as reagents, and finally using metal atoms as the key atom in a series of compounds designed to be radiolabeled markers of tumor hypoxia for positron emission tomography (PET) imaging. Finally I made the move to oncology to give my compounds a chance to be tested in a more biological setting. I am now the public engagement manager in the Department of Oncology at the University of Oxford, where I look for opportunities to discuss our science with school students, adult audiences and people who have been touched by cancer. During my spare time, I am the Adventure Training Officer for Thames Valley RAF Air Cadets, where I work to provide opportunities to allow young people to experience hill walking, climbing, paddlesport, and trail cycling. I am a keen hill walker myself and recently, made it to $6000 \mathrm{~m}$ in the Himalayas.
\end{abstract}

Accepted for publication: 7 November 2017; Published online: 29 June 2018

Keywords: education • engagement $\bullet$ outreach $\bullet$ public engagement $\bullet$ public understanding of science

Before you began your role as public engagement manager at the Department of Oncology at the University of Oxford, you were actively involved in the research \& development of one of the imaging tools that could potentially personalize cancer medicine. Can you tell us a little bit about this?

I was involved in the development of a PET tracer. At the moment, we use PET scans to look for sugar consumption. Tumors are metabolically very active and burn a lot of sugar so they shine on the scan which is looking at a chemical signature of sugar consumption, so the more sugar something consumes the brighter the glow. We were trying to design an agent that would allow the scan to look for oxygen concentration because we know that tumors that have a high oxygen concentration tend to respond to radiotherapy whereas tumors with a low concentration of oxygen tend not to respond to radiotherapy.

Following on from your research work what then inspired you to build your career in science, in particular oncology communication?

I had always taught chemistry at Oxford while I was still a chemist. When I moved into oncology as part of the development of the PET tracer, I stopped teaching for the University and I started training air cadets in my spare time. I was in the Gray Institute doing the research on PET when it became part of the Department of Oncology and so when the department started to make a decision that it wanted to give someone a full-time role in public engagement, I had both the interest and the practical and technical expertise to read and understand the science but also the background in training and teaching and communications. The two came together and I thought it sounded like an interesting combination that suited me well, so I made that move sideways.

Future Medicine 
What do you think needs to be done to engage people in science $\&$ technology $\&$ who would be responsible for this?

I think the really important thing for me about science communication and engagement is to make it an engagement. I really like it when there is a chance for a two-way conversation. The internet is amazing but it is a bit of a broadcast tool. When you can get members of the public actually looking a scientist in the eye you do a lot to demystify science, you allow the public to interrupt and change the direction of the conversation, you allow people to ask questions and request clarification. You also confront people with the idea that scientists for the most part are bright, young, enthusiastic, often female and that someone is actually looking a young scientist in the eye and hearing the passion and being able to ask questions. I think there is a really valuable space there and I think that the only answer to who is responsible for public engagement is everybody; institutes, funding agencies, groups need to give people space and permission to take an hour out and do some engagement as part of their job. Scientists need to see engagement as part of their development. This is an amazing way to develop communication skills and scientists need to take that opportunity, and then people need to turn up and listen to us. I do not think you can lay the responsibility for public engagement on one person but I do think having someone whose primary role is to facilitate and create opportunities and support scientists makes for a more dynamic and active public engagement program.

You work quite closely with schools \& various projects, how important is it to communicate cancer to young people, school age people \& get them excited about it from that early age?

I think it is critical because Oxford's Oncology Department is an extremely mixed environment - we make use of people with physics, biology, engineering, math, chemistry as well as medical degrees. I think from the perspective of teenage students they see medicine, they understand medicine, they do not necessarily understand what you would do with a degree in physics other than teach physics. That needs to be broken or we are going to run out of the sort of people who can do clinically important research in radiation biology and without them radiotherapy would not get better, and proton beams would not get better. Oxford University is very keen to reach people who would not normally apply to Oxford and those people are particularly vulnerable because they often do not have adults in their lives that can role model the fact that actually there are some really interesting and well-paid careers for a person whose head is based in math; among which are careers contributing to oncology.

\section{This year you hosted a session at the cancer conference on a beginners guide to cancer therapies: what are they \& how do they work? Can you summarize some of the key take-home points of your session for us?}

I was asked to do that session to allow the people who had come here with relatively little scientific background to get some initial tools to understand the rest of the sessions. We talked about how we might improve surgery by making the tumor more distinguishable to the eyes of a surgeon. We looked at some radiotherapy and in particular looked at how it works as a technique and how proton beam fits in against x-ray radiotherapy. Proton beams are really exciting and they present some challenges, so we looked at the challenges such as the fact that you need to know where the tumor is with precision; $\mathrm{x}$-rays are slightly sympathetic to not having that precision. We looked at chemotherapy and how even with classic chemo, there might be differences in how patients respond and that may be an opportunity to personalize the treatment. We looked at some of the targeting agents to help people understand how a cell works and therefore, how you might stick a spike in the wheels of a tumor cell and interrupt how a cell has become a tumor cell by dysregulating one piece of its machinery. And then we had a quick look at the idea that a cancer vaccine is actually a treatment not prevention and introduced the immunotherapy idea.

\section{Are you able to tell us about a specific upcoming project that you are working on at the moment?}

Having said that I really value face-to-face engagement, we are starting to look at a project to expand the more publicly understandable aspects of our website. Partly, as a way of providing more scientists an opportunity to develop their communication skills and partly, as a way of making sure that people who cannot get to meet us face-to-face have access to it. And so you might see something that starts to look like a blog come out on the department's website. 


\section{Do you have any closing comments for our audience?}

I think one of the reasons that I enjoy working in oncology; particularly in Oxford is I am quite hopeful about the sense that we are asking intelligent questions. It does not feel like we have a lot of answers necessarily but it feels like the questions we are asking are way more intelligent. Good questions have a chance at getting good answers whereas maybe 20 or 30 years ago, we were not asking such good questions and therefore, were doomed to get less good answers and so, I am quite excited by oncology.

\section{Disclaimer}

The opinions expressed in this interview are those of the interviewee and do not necessarily reflect the views of Future Medicine Ltd.

Financial \& competing interests disclosure

M Christlieb is employed by the Department of Oncology, University of Oxford. The authors have no other relevant affiliations or financial involvement with any organization or entity with a financial interest in or financial conflict with the subject matter or materials discussed in the manuscript apart from those disclosed.

No writing assistance was utilized in the production of this manuscript. 
